THE WABASH CENTER

JOURNAL on TEACHING

\section{Reviewed By}

Barbara A. Fears

Howard University

School of Divinity

BOOK REVIEW

\title{
Critical Race Theory in Teacher Education Informing Classroom Culture and Practice
}

\author{
Keonghee Tao Han and Judson Laughter, editors \\ New York, NY: Teachers College Press, 2019 (vii + 179 pages, ISBN 978-08077-6137-3, \\ \$37.95)
}

“I don't see race" is a statement that suggests a race-neutral or colorblind perspective. Race, however, delineates a power relationship, not a collection of phenotypic features (1). The contributing authors of this edited volume discuss the power dynamics in education, which they unanimously agree serve the interests of the hegemony, erase historical and contemporary injustices experienced by the subaltern, and uphold a particular sociopolitical perspective as normative. The normative hegemonic perspective is not restricted to race, but includes multiple, intersecting, socially constructed identities such as sexuality, ability and ethnicity. For these educators, whenever a hegemonic perspective is presented as normative in course material or in instructor attitudes, the experiences of the subaltern are disregarded, their voices muted, their experiential knowledge delegitimized, and all students miseducated. These scholars, therefore, challenge the notion of objective, context-neutral perspectives in educational encounters, and offer self-reflexive and classroom practices for teacher awareness and student engagement that make multiple subaltern experiences visible, their voices heard, and their experiences recognized as legitimate epistemology. Their insights have direct relevance to theological education.

Starting with critical race theory (CRT) as the analytical framework, scholars from a cross section of academic disciplines (such as early childhood development, adult learning, educational leadership, curriculum and instruction, and so forth) suggest methods for enhancing teacher literacy about biases in the classroom. The book is divided into three sections. Part I, "CRT and Teacher Education," describes the origin, evolution, and current use of CRT as an analytical tool for examining race and racism in education theory and practice. Part II, "Beyond Black and White," presents educational concerns from the LatinX, Asian, Native American, Queer, and anti-Blackness perspectives within CRT and highlights concerns specific to these communities such as: immigration, model minority stereotype, indigenous people, sexual identity, and the normalization of anti-Blackness. Part III, "Beyond CRT," examines Ghanaian, Fijian, Kenyan, and Confucian epistemologies and proposes an embrace of these non-western ways of knowing in teacher education. The final chapter prepares teachers to be agents of social change and proposes a pedagogy of compassion intended to transform power relationships in ways that respect human dignity and liberation (157).

Although the US is technically a former British colony, the shift to teacher education in a global context seemed abrupt and questionable for inclusion in a book about a theory (CRT) that originated in US law. Nevertheless, the insights and recommendations of the contributors speak to US theological education, which is experiencing increasing numbers of students of color, who both demand and deserve to have their stories reflected in the course curriculum, in the faculty who teach them, and in the administrators who make decisions concerning them by offering ways these institutions can be more sociopolitically inclusive. The authors also provide critical data about the educational formation of students both here and abroad, to religious educators, who employ and encourage narrative pedagogies (e.g., Engaged, Story Linking, Shared Christian Praxis), as well as to faculty and student recruiters. 